\title{
Exploring Emotional Intelligence Trait Enablers for Knowledge Sharing: An Empirical Study
}

\author{
Nóra Obermayer-Kovács \\ Faculty of Business and Economics, University of Pannonia, Hungary \\ obermayerkovacs@gtk.uni-pannon.hu \\ Edit Komlósi \\ Faculty of Business and Economics, University of Pannonia, Hungary \\ editkomlosi@gtk.uni-pannon.hu \\ Cintia Szenteleki \\ Faculty of Business and Economics, University of Pannonia, Hungary \\ szenteleki.cintia@gmail.com \\ Erika Viktória Tóth \\ Faculty of Business and Economics, University of Pannonia, Hungary \\ toth@mik.uni-pannon.hu
}

\begin{abstract}
Purpose: The presented paper aims to reveal the relationship between emotional intelligence and knowledge sharing of employees of Hungarian organisations. Furthermore, the emphasis is placed on identifying the specific emotional intelligence traits which enable knowledge sharing.

Design/methodology/approach: The database includes 215 full questionnaires collected via LimeSurvey system. The research has applied quantitative methodology. After the Hungarian validation of TEIQUe (Petrides, 2009) emotional intelligence measurement and Kankanhalli's Knowledge Sharing scale (Kankanhalli et al., 2005), correlation analyses have been adopted to test the hypotheses.

Findings: Significant positive relationship can be identified between employees' emotional intelligence and knowledge sharing behaviour. Well-being, emotionality, self-control and sociability as emotional intelligence factors show relation to altruism, loss of knowledge and reputation. Among individual factors, differences can be identified regarding generation and position, while gender and education do not seem to play a significant role in this relationship. Regarding organisational characteristics, differences can be detected according to the size of the organisation.

Practical implications: The outcome of the research can help companies, managers and HR specialists to learn how to trigger knowledge sharing behaviour according to gender and position while taking the size of the organisation into consideration.
\end{abstract}

\section{Psynargia}

International Journal of Synergy and Research Vol. 4, No. 1, 2015 p. 7-21 
8

IJSR

4,1
Original value: The original value of the research is that specific emotional intelligence traits have been identified to detect knowledge sharing behaviour regarding individual and organisational characteristics. The presented paper has been the first study to carry out applying trait emotional intelligence measurement in relation to knowledge sharing.

Keywords: knowledge sharing, trait emotional intelligence, generation difference, Hungarian organisations.

Article type: Research paper.

\section{Introduction}

In the era of knowledge economy, knowledge is increasingly seen as the most important strategic asset. Individual knowledge workers play central role in the creation of value and the development of strategies. Organizations have an urgent need to focus on innovation with respect to new products and services. A fundamental precursor of such innovation is effective knowledge sharing. A significant part of the knowledge possessed by an organization is within the knowledge workers. Thus, it is important to understand what encourages individuals to share their knowledge and what holds them back from sharing it. Employees' willingness to share knowledge can be influenced by not only organizational factors but also individual factors like people behaviours, motives and characteristics. Emotional intelligence can be one of the individual factors that can play an important role in forming their knowledge sharing endeavours. The authors are convinced that a personality trait-based emotional intelligence measuring device may contribute to find deeper connections to what emotional intelligence factors facilitate and / or impede knowledge sharing.

\section{Literature review}

\subsection{Emotional intelligence}

According to Benson (2010), emotional intelligence covers the process of managing personal social and environmental changes by coping with a situation, solving problems and making decisions immediately, realistically and flexibly. It is a set of abilities related to processing emotions and emotional information (Côté et al., 2010).

Güllüce and İşcan (2010) describe emotional intelligence as a combination of needs, motives and real values to manage individuals' attitudes that connects to human relations and determines the success in the workplace. Grace (2012) has found that emotional intelligence and capabilities are essential in success. Chopra and Kanji (2010) also argue that emotional intelligence can help in managing relations, understanding emotions, motivating and leading others.

Luu (2013) states that emotional intelligence can activate behaviour and acts as a layer between cognition and behaviour. It has to be seen that high emotional intelligence level can help not only to manage our own emotions but also to manage emotions of others. This statement is highly supported in case when another person reacts with egoism or arrogance to shared knowledge or when he or she has too low self-efficiency to learn from others (van der Hoof et al., 2012).

Darabi (2012) argues that emotional intelligence is one of the most important human mechanisms that involves the ability to adapt the environment. Chin (2013) has 
determined emotional intelligence as a tool that employees use to detect all workerrelated emotions, and also for emotional self-management, motivation and social skills.

As this paper emphasises trait emotional intelligence, it can be examined by four main factors. Petrides (2009) determined 15 components of emotional intelligence and categorized them into four factors: Emotionality, Self-control, Sociability and Wellbeing. Emotionality factor is defined as individuals' ability to relate to their and other people's feelings, as well as to perceive and express emotions in favour of developing and sustaining close relationships. At item level it includes empathy, emotion perception, emotion expression and relationships. Self-control factor is identified as individuals' ability to control their urges and desires. They can regulate external pressures and stress effectively. The following items are included within this factor: stress management, impulsiveness and emotion regulation. Sociability factor is a notion which concerns social relationships and social influence such as the individuals' ability to be better in social interactions with listening carefully and communicating clearly and confidently. This factor includes emotion management, assertiveness and social-awareness items. Well-being refers to the generalized sense of wellbeing (including past achievements and future expectations) when individuals with high level of well-being are positive, happy and fulfilled. This factor consists of happiness, optimism and self-esteem facets.

Research papers appearing in significant journals (e.g. Journal of Applied Psychology, Personality and Individual Difference Journal, Personality and Social Psychology Review) argued the importance of learning and developing the abovementioned emotional intelligence traits to be able to apply them effectively in private and work life (Gardner and Qualter, 2010).

\subsection{Knowledge sharing}

Nowadays knowledge is considered a key element of competitiveness and becomes a main component of value-added production. In any organization, knowledge can be determined as a rich source of competitive advantage (Arabshahi et al., 2013). Within a knowledge economy information and data effectively overshadow physical assets (Thakur et al., 2013) and companies uncover most opportunities - and derive the value - from one intellectual asset in particular: knowledge (Coveo, 2013). This makes knowledge management a key strategic field which facilitates improving performance. Knowledge sharing is a substantial area of knowledge management located within knowledge process where knowledge is generated and applied (Arabshahi et al., 2013).

Knowledge sharing is considered to be one of most important aspects of knowledge management (Gupta et al., 2000) and the success of knowledge management initiatives depends on knowledge sharing (Wang et al., 2010). Knowledge-sharing activities provide members of groups with the opportunities to exchange ideas and to cooperate, and in this way the performance success of their organization can be maximized (Dokhtesmatia and Ghorbani, 2013). Knowledge sharing is a two-way process between the knowledge giver(s) and the knowledge receiver(s) (Gaál et al., 2013). The way knowledge is shared within the organization is essential not only to the success of the organization, but also to those who take part in the knowledge sharing process and would benefit from it (Szabó and Csepregi, 2013).

\author{
Exploring \\ Emotional \\ Intelligence \\ Trait Enablers \\ for Knowledge \\ Sharing: \\ An Empirical \\ Study
}


IJSR 4,1
Research works have proved that intrinsic and extrinsic motivators influence knowledge sharing attitude. It is stated also that intrinsic motivation plays a greater role than extrinsic motivation in case of willingness to share. Extrinsic motivation group involves reputation, reciprocity, and organizational reward while intrinsic motivation is based on altruism (Davenport and Prusak, 1998; Susanty and Wood, 2011). Reputation covers those processes of knowledge sharing that mean economic and social benefits, for example to have better image or to enjoy increased prestige (Kankanhalli et al., 2005; Zhang et al., 2009; Chen, 2011). Reciprocity can be determined as a set of expectations, with which the employee can maintain a reciprocal exchange and friendly relationship with others. This motivation positively influences knowledge sharing intention (Tsai et al., 2012; Chennamaneni, 2012). Organizational reward means the importance of economic incentives (e.g. bonuses, security, and career advancement) provided for individuals (Hall, 2001). Altruism can be considered as individuals' willingness to act on a voluntary basis to the benefit and the well-being of others without anticipating anything in return (Kankanhalli et al., 2005; Chai and Kim, 2010). Loss of knowledge power is the perception of power and unique value lost due to knowledge contributed (Gray, 2001). Knowledge management literature reports the loss of knowledge power as a barrier to knowledge sharing. People may keep themselves out of a knowledge exchange if they feel they can benefit more by hoarding their knowledge rather than by sharing it (Davenport and Prusak, 1998).

\subsection{Knowledge sharing and emotional intelligence}

Abzari et al. (2014) have identified that social and emotional competence have an impact on employees' knowledge sharing behaviour. Also, the effect of emotional intelligence competency has been proved to be positive and significant on knowledge sharing behaviour.

Emotional intelligence intermediates between the cognitive and behavioural layer and people with high emotional intelligence think and act more socially, especially in the case of knowledge sharing. Basically high emotional intelligence means a psychological safety that encourages knowledge sharing (Kessel et al., 2012).

Arakelian et al. (2013) have conducted a structural equation modelling between emotional intelligence and knowledge sharing. Their research pinpoints a meaningful positive relationship between the two areas. Moreover, it has found positive relationships among three dimensions of emotional intelligence: self-awareness, social-awareness and relation management and knowledge sharing.

Gupta (2008) after examining postgraduate students in relation to emotional stability and knowledge sharing behaviour has proved that people with higher emotional stability would be more self-confident, more secure and fear less to be involved in knowledge sharing activities. On the other hand, he has examined not only the giver but the receiver part of knowledge sharing and has found that accepting knowledge should be voluntary without forcing and with reconciliation between parties. It also confirms that communication plays an important role in sharing knowledge and this way emotional intelligence can strengthen the communication and knowledge sharing. Knowledge 
management - among other factors - is a component of organisational intelligence. These components among others include information processing and adaptation skills which related to some literatures are related to emotional intelligence (Yeniçeri and Demirel, 2007; Kalkan, 2004).

According to Kalkan's (2004) organisation learning process model, organisational knowledge production process is based on organisational learning which is embedded in the organisational intelligence. Each group has several factors and it has to be seen that emotional intelligence builds a part of organisational intelligence and knowledge acquisition, dispersion, the interpretation of knowledge and knowledge storing, and these are forming the group of organisational learning. The third group is called organisational knowledge production process and it involves sharing tacit knowledge. So Kalkan's model shows that emotional intelligence and knowledge sharing both have place in organisational learning process and they have significant relations within this model. Dogan's (2003) model that describes the circle of development and sharing of tacit knowledge, has also proven that sharing tacit knowledge is based on emotional intelligence.

Othman and Abdullah (2009) have created a model that expresses relationships between emotional intelligence and tacit knowledge sharing. It shows that emotional intelligence and its dimensions affect teamwork and organisational citizenship behaviour of team members and also helps in achieving knowledge sharing.

Karkoulian et al. (2010) argue the importance to change employees' behaviour and attitudes in order to share their knowledge. They declare that emotional intelligence can play a key role in this process. This way emotional intelligence can be described as a source of human energy, information, connection and influence that helps in changing attitudes.

Organizations realize the key factors of knowledge sharing. It is stated that human factors and people's identity are fundamental for their motivation and commitment. It is proven that emotional intelligence has positive influence on knowledge sharing, that employees with high emotional intelligence are more likely to ignore their personal interest in favour of their team's effectiveness, and that they tend to share their experiences and knowledge more likely (Othman et al., 2008; Karkoulian et al., 2010). Özler et al. (2012) also proved positive relationship between dimensions of knowledge sharing and dimensions of emotional intelligence.

Employees' tendency to share their knowledge is affected by not only organisational but also individual factors. As it has been already mentioned, in order to encourage employees to knowledge sharing, changes are necessary in their behaviours and attitudes, and emotions are the source of behaviour. Emotional intelligence plays an important role in tendency of sharing knowledge (Cote and Miners, 2006; Lindebaum, 2009). Individuals can find knowledge sharing costly and uncomfortable, so to make them feel sharing knowledge is socially good and benefits the organisation is really important. Basically, if an employee has high emotional intelligence, he or she has more tendency to share knowledge. So emotional intelligence can be an essential aspect in influencing knowledge sharing positively (Constant et al., 1994; Karkoulian et al., 2010).

Lindebaum (2009) after examining both the correlations between knowledge sharing and emotional intelligence and the influence of factors of emotional intelligence

\author{
Exploring \\ Emotional \\ Intelligence \\ Trait Enablers \\ for Knowledge \\ Sharing: \\ An Empirical \\ Study
}




\section{2}

IJSR 4,1

has found the following. Within the self-awareness factor, if an employee is aware of his/her senses and mood shifts he/she would be more likely to assess the situation when deciding about knowledge sharing. Concerning self-management, an employee is able to decide objectively under different circumstances. Social awareness and relationship management can help show empathy and stimulate knowledge sharing behaviour.

In other words, the motivation of knowledge sharing can be based on emotional intelligence rate: with higher inner motivation, people are more likely to share their knowledge because of altruism that is based on intrinsic motivation (Wang and Hou, 2015). That is the reason why this relationship among emotional intelligence and the motivations of knowledge sharing have been decided to be examined.

\section{The presented research and research methodology}

Based on our literature review, a large-scale online survey - "Knowledge sharing and emotional intelligence in Hungary 2014/2015" - was developed, which was carried out in LimeSurvey, a web application. In the short introduction to the survey, it was stressed that the answers would be anonymous and only used for this study. Respondents could leave their e-mail address in order to be informed about the results later. More than 2000 individuals received an e-mail requesting 15 minutes of their time to fill in a questionnaire. The survey instrument consisted of organizational and demographic questions; twenty-two statements related to knowledge sharing and thirty statements related to emotional intelligence. The potential respondents were from networks of University of Pannonia and the researchers' social circles. The participation in the study was voluntary. In the course of the survey, answers from 215 organizations were included in the database. The completed questionnaires were exported from LimeSurvey to Excel files and analysed using SPSS. The field study was conducted in Hungary, over a period of 3 months, from November 2014 till the end of January 2015. The participating organizations were all operated in Hungary.

\subsection{Hypotheses}

Based on previous literature and research outcomes the following hypotheses were formulated:

H1. There is a relation between employees' emotional intelligence level and their knowledge sharing behaviour.

H2. The relationship between emotional intelligence level and knowledge sharing differs at factorial levels.

H3. Individual characteristics have relationship with knowledge sharing behaviour and emotional intelligence.

H4. Organisational characteristic have relationship with knowledge sharing behaviour and emotional intelligence. 


\subsection{Model}

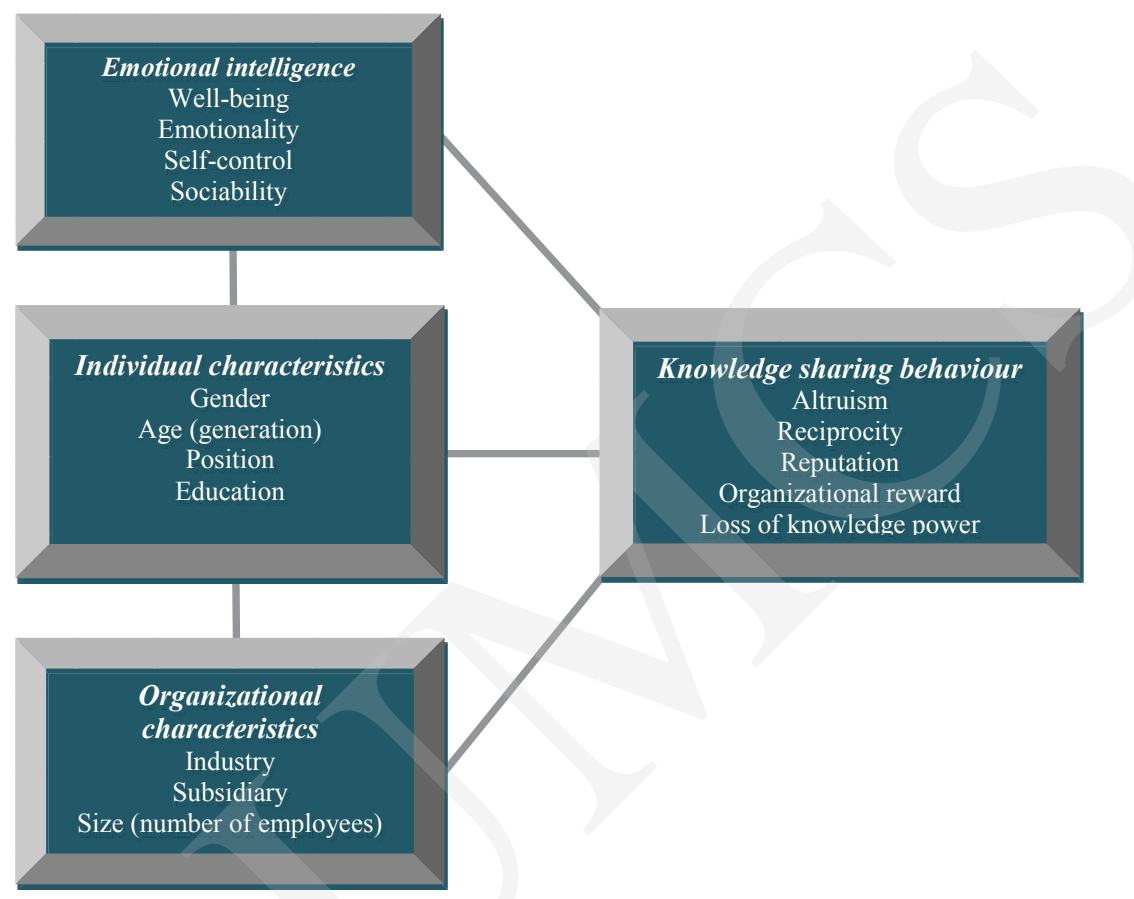

Exploring

Emotional

Intelligence

Trait Enablers

for Knowledge

Sharing:

An Empirical Study
Figure 1:

The research model

(own)

\subsection{Variables and measurements}

In the research, two international measurements were adopted in Hungarian: the Trait Emotional Intelligence Questionnaire (TEIQue) by Petrides (2009) and Knowledge Sharing scale by Kankanhalli (Kankanhalli et al., 2005). In order to apply these measurements, the reliability had to be checked. Reliability of instrument scales were measured by reliability coefficient, Cronbach's alfa. Generally, a questionnaire with an $\alpha$ of 0.8 is considered reliable. Hence, this questionnaire certainly is reliable, since the $\alpha$ for Knowledge sharing was 0.844 and for Emotional intelligence was 0.879. Internal validity refers to the extent to which the research design really allows the researcher to draw conclusions about the relationships among variables. Hence, it can be concluded that the sample had a normal distribution.

\section{Data analysis}

\subsection{Descriptive statistics}

Most of the 215 respondents were females (54\%) and belonged to three generations: $16.3 \%$ were Baby Boomers, 48.8\% from Generation X and 34.9\% from Generation Y. A majority of respondents had university degrees: master $(50.7 \%)$ or bachelor 


\section{4}

IJSR

4,1

(36.7\%). $25.6 \%$ of the respondents were top managers, $29.5 \%$ were middle level managers and $44 \%$ were white collar workers. Most of the participants had maximum 10 years of tenure. Based on the number of employees, $45.6 \%$ were large companies, $20.5 \%$ were medium-sized enterprises, $22.3 \%$ were small businesses and $11.6 \%$ were micro businesses. Somewhat more than half of the organizations (61.4\%) were national (Hungarian-owned) companies and $38.6 \%$ were subsidiaries of foreign companies.

\subsection{Hypothesis testing} Testing H1

After examining normal distribution, significant positive correlation could be identified between global emotional intelligence and knowledge sharing (.14). The global relationship between the two variables was further examined on a factorial level.

\section{Testing $\mathbf{H} 2$}

\section{Global emotional intelligence and knowledge sharing factors}

The examination of possible relationships among global emotional intelligence and all factors of knowledge sharing showed that three out of the five factors had significant positive relationships with global emotional intelligence level: altruism (.24), reputation (.16) and loss of knowledge (.19). It means that people with high overall emotional intelligence are more likely to share their knowledge within the factor of altruism and reputation, and they are not afraid of losing knowledge.

\section{Global knowledge sharing and emotional intelligence factors}

The analysis showed that only one factor, well-being, had significant positive relationship with global knowledge sharing (.20). The willingness to share knowledge is influenced by well-being, which means that the higher an individual's well-being level is, the greater willingness to share knowledge can be detected.

\section{Well-being}

According to the correlation analysis, there were significant positive relationships between well-being and the factor of altruism (.29). There were also positive correlations between well-being and loss of knowledge power (.18) and reputation (.15). It means that employees with higher level of well-being are more likely to share their knowledge based on altruism, enhanced image, and they are not afraid of losing their knowledge power.

\section{Emotionality}

In relation to emotionality, it could be seen that the same two factors of knowledge sharing indicated relationships as well as self-control. There were significant positive relationships between emotionality and altruism (.16) and emotionality and loss of knowledge power (.15). In other words, higher emotionality results in higher altruism and represents less fear of knowledge loss. 


\section{Self-control}

According to the correlation table, there was a significant positive relationship between self-control and altruism (.15) and self-control and loss of knowledge (.17). It means that higher self-control involves higher rate of altruism and also that the person who shares knowledge is not afraid of losing knowledge.

\section{Sociability}

In relation to sociability, it could be seen that there was a positive relationship with reputation (.17). It indicates that employees with higher sociability traits share knowledge because they consider their reputation.

\section{Testing H3}

\section{Gender}

Related to descriptive statistical analysis, there were no significant differences between men and women. It means that gender did not have an impact on global emotional intelligence or global knowledge sharing. At factorial level, the research results showed that females had higher emotionality level and males had higher self-control and sociability levels. The results support previous trait emotional intelligence outcomes. The research could not detect relationships with any of the knowledge sharing factors.

\section{Generation}

Kruskal Wallis Test was applied to examine the difference between the generations, the positions and the types of educational levels. Significance levels are indicated in brackets and further analyses were based on the medians.

In terms of generation, there was no significant relationship between the global emotional intelligence and global knowledge sharing. However, at the factor level there were differences in relation to one of the emotional intelligence's factor: self-control (sig .031) and two of the knowledge sharing's factors, organizational reward (sig .000) and loss of knowledge power (sig .000). Median values showed that members of Generation $\mathrm{X}$ has the highest self-control level, thereafter Baby-Boomers while Generation Y has the lowest level of self-control. Nevertheless, it has to be emphasised that these results were not significant.

The younger the respondent (Generation Y) was, the more he/she could be motivated by organisational reward to share knowledge. With loss of knowledge power the opposite of the previous statement could be determined. The younger the respondent was, the more he or she was afraid of losing knowledge power.

\section{Position}

The research examined the impact of employees' position on global emotional intelligence. The results showed that the higher the position was, the higher the global emotional intelligence level got (sig .004). Similarly, at factorial level, the higher the position was, the higher the level of sociability rose (sig .001). Furthermore, managers' emotionality was higher than office employees' emotionality (sig .045), while the level of middle managers' self-control (sig .013) was higher than people in other positions.

\author{
Exploring \\ Emotional \\ Intelligence \\ Trait Enablers \\ for Knowledge \\ Sharing: \\ An Empirical \\ Study
}




\section{6}

IJSR

4,1

The research also investigated the impact of employees' position on global knowledge sharing but no relationship could be detected. At factor level, the relationship could be identified with two factors of knowledge sharing. The factors were loss of knowledge power (sig .016) and organisational reward (sig .002). Office employees appeared to be more afraid of losing their knowledge power than the managers at higher positions. The opposite can be detected in relation to organizational reward, which means the lower the position, the higher the need for organisational reward.

\section{Education}

The research examined the relationships between the participants' level of education and emotional intelligence and knowledge sharing behaviour, but the analyses could not detect any kind of connections.

\section{Testing H4 \\ Industry}

This research also aimed at investigating possible differences among sectors. The answers of 215 companies did not allow examining this relationship because of the lack of representativeness and the diversity of companies. It can be a possible subject for further research.

\section{Subsidiary}

The research could examine the possible difference among companies according to their ownership: domestic or foreign. It can be seen there is no significant difference among Hungarian companies and subsidiaries of foreign companies related to both emotional intelligence and knowledge sharing.

\section{Size}

Examining relations among the size of the companies and knowledge sharing factors, it could be identified that size and loss of knowledge indicated significant difference (sig. 006). Larger companies were less afraid of losing knowledge than smaller ones as medians show. On the other hand, there was no such significant difference related to emotional intelligence and size of companies.

\section{Discussion and conclusion}

This empirical research indicated many novel outcomes. Among others, it could confirm the significant positive relationship between employees' emotional intelligence and knowledge sharing behaviour. It can be stated that those employees who had high wellbeing level are more willing to share their knowledge. Feeling optimist, happy and having high self-esteem level inevitably assumes a positive attitude towards knowledge sharing. Those with high emotionality and self-control level were less afraid of losing their knowledge and more willing to share it. One of the possible reasons behind it is that people with high empathy and relationship care can build more trust; therefore knowledge sharing becomes natural. The other reason is that high stress and emotional 
management can make employees not fear sharing their knowledge. Sociability factor showed correlation with reputation. It can be stated that assertive communication and social awareness, as part of emotional intelligence sociability factor, enable employees to share their knowledge because of reputation possibilities.

Among the age groups, generation $\mathrm{X}$ indicated higher self-control level. Furthermore, Generation $\mathrm{Y}$ was the most afraid to loose knowledge but also the most willing to share knowledge for organisational reward. Generation $\mathrm{X}$ has the greatest value because currently it is the ,sandwich-generation” between baby-boomers and Generation Y on the job market and they have to find the best ways to accommodate older and younger colleagues. Generation $\mathrm{X}$ is good at regulating pressure and stress (both internal and external), they can easily control their desires and urges. Baby-boomers had to learn that they can mostly prevail if they can exercise self-control. Members of Generation $\mathrm{Y}$ were born to the age where there are no limits. They can easily find and share almost everything in the world of internet and social media. This generation is intense, young, impulsive, the least cautious and makes decisions on the spot.

Young people can learn more quickly and easily which is why they realise that if they share knowledge, their organisational reward is going to grow. In this case, they also get positive feedback from the organisation. The opposite is true for older generations because they already had organisational experience and a position where they do not necessarily want to change so they do not really need organisational reward to share their knowledge. Young people are afraid of knowledge power loss due to pressure from strong competition: they may think the more knowledge they retain, the more competitive advantage they gain on the job market.

As for position, the level of emotional intelligence grew as the employees climbed the career ladder, especially within the sociability factor. Interestingly, this was not the case with education level, which supports previous research debates that emotional intelligence and IQ are separate and emotional intelligence plays a vital role in gaining higher position. Top managers have relationships with people from various areas. Networking is important at this level since they can handle these situations easier if they are good at social interactions. Middle managers have the highest emotionality level, because they have to perceive and express emotions, develop and sustain close relationships both with top managers and their office employees. They have a wide range of emotion-related skills. The reason why self-control of middle managers was higher than that of employees from other positions is that middle managers have to adapt to upper and lower organisational levels as well.

On the other hand, the higher an employees' position, the less afraid they were to lose knowledge. However, office workers were willing to share knowledge in favour of their reputation. The background reason can be that they also lose their competitive advantage over others. This advantage can help them progress, get nominations, improve in the future, etc. Top managers are not worried about losing their knowledge and they are the least interested in organisational reward.

Considering organisational characteristics, no significant difference could be detected between national (Hungarian) and international companies subsidiaries. However, significant difference could be pinpointed in relation to the size: the smaller an organisation, the more afraid it was to lose knowledge. The reason could be very

\author{
Exploring \\ Emotional \\ Intelligence \\ Trait Enablers \\ for Knowledge \\ Sharing: \\ An Empirical \\ Study
}


IJSR 4,1

obvious as micro and small businesses are specialised and that is why their knowledge is a key to success on the market.

\section{Limitation and future research}

The presented paper is limited by the data in a sense that it was too small to do an industrial segmentation analysis. The majority of data came from IT and commerce. Future research can focus on gathering more information from other industrial segments. Furthermore, other counties can be involved to identify similarities and differences and to see if culture has any influence. The authors of this paper have already contacted researchers from other countries to carry out studies together. Future research may focus on going deeper into the analysis of emotional intelligence and knowledge sharing facet levels.

\section{References}

Abzari, M., Shahin, A. and Abasaltian, A. (2014), "Developing A Conceptual Framework For Knowledge Sharing Behavior By Considering Emotional, Social And Cognitive Intelligence Competencies", Kuwait Chapter of Arabian Journal of Business and Management Review Vol. 4, No. 1.

Arabshahi, M., Lagzian, M., Rahimnia, F. and Kafashpour, A. (2013), "The impact of emotional intelligence on faculty members' knowledge sharing behaviors", Management Science Letters, Vol. 3, No. 12, pp. 2963-2970, ECONIS, EBSCOhost, (accessed February 3, 2015).

Arakelian, A., Maymand, M.M. and Hosseini, M.H. (2013), "Study of the relationship between Emotional Intelligence (EI) and Knowledge Sharing (KS)", European Journal of Business and Management, Vol. 5, No. 32.

Baruch, Y. and Lin C. (2012), "All for one, one for all: Coopetition and virtual team performance", Technological Forecasting \& Social Change Vol. 79, Contains Special Section: Actors, Strategies and Resources in Sustainability Transitions, pp. 1155-1168.

Benson, G., Ploeg, J. and Brown, B. (2010), "A cross-sectional study of emotional intelligence in baccalaureate nursing students", Nurse Education Today, Vol. 30, pp. 49-53. DOI: http:// dx.doi.org/10.1016/j.nedt.2009.06.006

Bilińska-Reformat, K. and Sztangret, I. (2013), "Influence of knowledge sharing between intermediaries and IT leaders on developing offers for customers - Polish perspective" International Journal Management Cases, Vol. 15, No. 4, p. 205.

Chai, S. and Kim, M. (2010), "What makes bloggers share knowledge? An investigation on the role of trust", International Journal of Information Management, Vol. 30, No. 5, pp. 408415. DOI: http://dx.doi.org/10.1016/j.ijinfomgt.2010.02.005

Chen, Z. (2011), "The Interactive Effects of Relationship Conflict, Reward, and Reputation on Knowledge Sharing", Social Behavior \& Personality: An International Journal, Vol. 39, No. 10, pp. 1387-1394. DOI: http://dx.doi.org/10.2224/sbp.2011.39.10.1387

Chennamaneni, A., Teng, J.T.C. and Raja, M.K. (2012), “A unified model of knowledge sharing behaviours: Theoretical development and empirical test", Behaviour \& Information Technology, Vol. 31, No. 11, pp. 1097-1115. DOI: http://dx.doi.org/10.1080/014492 9X.2011.624637

Chin, H.C. and Chen, H.T. (2013), "The effect of emotional intelligence on job satisfaction of vocational high school teachers", Business and Information, pp. 267-273. 
Chopra, P., and Kanji, G. (2010), "Emotional Intelligence: A catalyst for inspirational leadership and management excellence" Total Quality Management, Vol. 21, No. 10, pp. 971-1004. DOI: http://dx.doi.org/10.1080/14783363.2010.487704

Constant, D., Kiesler, S. and Sproull, L. (1994), "What's mine is ours, or is it? A study of attitudes about information sharing", Information Systems Research, Vol. 5, No. 4, pp. 400-421. DOI: http://dx.doi.org/10.1287/isre.5.4.400

Côté, S., Lopes, P.N., Salovey, P. and Miners, C.T.H. (2010), "Emotional intelligence and leadership emergence in small groups a University”, The Leadership Quarterly, Vol. 21, pp. 496-508.

Cote, S., and Miners, C. (2006), "Emotional intelligence, cognitive intelligence and job performance", Administrative Science Quarterly, Vol. 51, No. 1, pp. 1-28. DOI: http:// dx.doi.org/10.1016/j.leaqua.2010.03.012, http://dx.doi.org/10.1016/j.leaqua.2010.06.012

COVEO (2013), "E-book of Measuring Return on Knowledge in a Big Data World" available at: http://www.coveo.com/en/ebooks-white-papers/ebook/Measuring-Return-on-Knowledgein-a-Big-Data-World (accessed February 3, 2013).

Darabi, M. (2012), "Emotional Intelligence: A literature review", Journal of Applied Sciences Research, Vol. 8, No. 6, pp. 2991-2997.

Davenport, T. and Prusak, L. (1998), Working Knowledge: How Organizations Manage What They Know, Boston, M.A.: Harvard Business School Press.

Doğan, H. (2003), "An Analysis of Tacit Knowledge with Humanistic Approach: Strategic Using Ways and the role of Emotional Intelligence and Body Language in Developing and Sharing Tacit Knowledge", Ege Academic View, Vol. 3, No. 1-2, pp. 58-66.

Dokhtesmatia, M. and Ghorbani, B.R. (2013), "Knowledge Sharing in Iranian academic institutions: Meta analysis approach", Procedia - Social and Behavioral Sciences 73, Proceedings of the 2nd International Conference on Integrated Information (IC-ININFO 2012), Budapest, Hungary, August 30 - September 3, 2012, pp. 383-387.

Gaál, Z., Szabó, L., and Csepregi, A. (2013), "Organizational characteristics that influence the way middle managers and their subordinates are available to each other", Proceedings of 14th European Conference on Knowledge Management (ECKM 2013), Kaunas, Lithuania, pp. 227-235.

Gardner, K.J. and Qualter, P. (2010), "Concurrent and incremental validity of three trait emotional intelligence measures", Australian Journal of Psychology, No. 62, pp. 1-13. DOI: http:// dx.doi.org/10.1080/00049530903312857

Grace, A.F. (2012), "Emotional Intelligence and Gender as Predictors of Academic Achievement among Some University Students in Barbados", International Journal of Higher Education, Vol. 1.

Gray, P.H. (2001), "The Impact of Knowledge Repositories on Power and Control in the Workplace", Information Technology and People, Vol. 14, No. 4, pp. 368-384. DOI: http:// dx.doi.org/10.1108/09593840110411167

Güllüce, A.Ç. and İşcan, Ö.F. (2010), "The Relationship between Occupational Burnout and Emotional Intelligence", Eskişehir Osmangazi University Business and Management Faculty Review, Vol. 5, No. 2, pp. 7-29.

Gupta, A.K. and Govindarajan, V. (2000), "Knowledge management's social dimension: Lessons from Nucor Steel”, Sloan Management Review, Vol. 42, No. 1, pp. 71-80.

Gupta, B. (2008), "Role of Personality in Knowledge Sharing and Knowledge Acquisition Behaviour", Journal of the Indian Academy of Applied Psychology, Vol. 34, No. 1, pp. 143-149.

Hall, H. (2001), "Input-friendliness: Motivating Knowledge Sharing Across Intranets", Journal of Information Science, Vol. 27, No. 2, pp. 139-146. DOI: http://dx.doi. org/10.1177/016555150102700303

Kalkan, V.D. (2004), "New Initiatives in Organisational Learning Studies; Organisational Intelligence and Information producing", 3rd National Information, Economics and Management Congress Final Paper, Osmangazi University, Eskişehir, 2004, p. 405.

\author{
Exploring \\ Emotional \\ Intelligence \\ Trait Enablers \\ for Knowledge \\ Sharing: \\ An Empirical \\ Study
}


IJSR

4,1
Kankanhalli, A., Tan, B.C.Y., and Wei, K.K. (2005), "Contributing knowledge to electronic knowledge repositories: An empirical investigation", MISQuarterly, Vol. 29, No. 1, pp. 113-143.

Karkoulian, S., Harake, N. and Messarra, L.C. (2010), "Correlates of Organizational Commitment and Knowledge Sharing via Emotional Intelligence: An Empirical Investigation", The Business Review, Cambridge, Vol. 15, No. 1 Summer, pp. 89-96.

Kessel, M., Kratzer, J. and Schultz, C. (2012), "Psychological safety, knowledge sharing, and creative performance in healthcare teams", Creativity and Innovation Management, Vol. 21, No. 2, pp. 147-157. DOI: http://dx.doi.org/10.1111/j.1467-8691.2012.00635.x

Lindebaum, D. (2009), "Rhetoric or Remedy? A critique on developing emotional intelligence", Academy of Management Learning \& Education, Vol. 8, No. 2, pp. 225-237. DOI: http:// dx.doi.org/10.5465/AMLE.2009.41788844

Luu, T. (2014), "Knowledge sharing and competitive intelligence", Marketing Intelligence \& Planning, Vol. 32, Issue 3, pp. 269-292. DOI: http://dx.doi.org/10.1108/MIP-05-2013-0077

Othman, A.K. and Abdullah, H.S (2008), "The Influence of Emotional Intelligence on Tacit Knowledge Sharing in Service Organizations", Knowledge management in emerging economies: social, organizational and cultural implementation, pp. 171-185.

Othman, A.K., Abdullah, H.S. and Ahmad, J. (2008), "Emotional intelligence, emotional labour and work effectiveness in service organisations: A proposed model", Vision (09722629), The Journal of Business Perspective, Vol. 12, No. 1, pp. 31-42. DOI: http://dx.doi. org/10.1177/097226290801200105

Özler, D.E., Mercan, N., Aksanyar, Y., and Altinay, A. (2012), “A research on the relationship between knowledge sharing and emotional intelligence in the process of knowledge management", The Journal of Knowledge Economy \& Knowledge Management, Vol. 7, No. 2, pp. $117-132$.

Petrides, K.V. (2009), „Technical manual for the Trait Emotional Intelligence Questionnaires (TEIQue)", London: London Psychometric Laboratory.

Susanty, A.I. and Wood, P.C. (2011), "The Motivation to Share Knowledge of the Employees in the Telecommunication Service Providers in Indonesia", International Proceedings of Economics Development \& Research, Vol. 5, Issue 2, p. V2-159.

Szabó, L. and Csepregi, A. (2013), "Organizational characteristics and methodological competences - Are there difference within methodological competences needed for thinking and used for work method and style based on the characteristics of the organization", Management and Marketing - Challenges for the Knowledge Society, Vol 8, pp. 353-362.

Thakur, V. and Sinha, S. (2013), "Knowledge Management in an Indian Perspective", The SIJ Transactions on Industrial, Financial \& Business Management (IFBM), ISSN: 2321 - 242X, Vol. 1, No. 1, pp. 7-12.

Tsai, M., Chen, K., and Chien, J. (2012), "The factors impact of knowledge sharing intentions: the theory of reasoned action perspective", Quality \& Quantity, Vol. 46, No. 5, pp. 1479-1491. DOI: http://dx.doi.org/10.1007/s11135-011-9462-9

van den Hooff, B., Schouten, A.P. and Simonovski, S. (2012), "What one feels and what one knows: the influence of emotions on attitudes and intentions towards knowledge sharing", Journal of Knowledge Management, Vol. 16, No. 1, pp. 148-158. DOI: http://dx.doi. org/10.1108/13673271211198990

Wang, W., and Hou, Y. (2015), Motivations of employees' knowledge sharing behaviors: A selfdetermination perspective. Information \& Organization, 25(1), 1-26, DOI:10.1016/j. infoandorg.2014.11.001; DOI: http://dx.doi.org/10.1016/j.infoandorg.2014.11.001

Wang S. and Raymond, A.N. (2010), "Knowledge sharing: A review and directions for future research", Human Resource Management Review, Vol. 20, pp. 115-131. DOI: http://dx.doi. org/10.1016/j.hrmr.2009.10.001 
Yeniçeri, Ö. and Demirel, Y. (2007), “A Study on Organizational and Individual Impediments against Knowledge Sharing in Organizations" Selçuk University Karaman Business and Management Faculty Review, Vol. 12, No. 9, pp. 21-234.

Zhang, X., Chen, Z., Vogel, D., and Guo, C. (2009), "Exchange ideology as a moderator of knowledge sharing in virtual teams: A social exchange theory perspective", International Journal of Internet and Enterprise management, Vol. 6, pp. 143-163. DOI: http://dx.doi. org/10.1504/IJIEM.2009.023927

\section{Biographic Notes}

Nóra Obermayer-Kovács is an Assistant Professor at the Department of Management, University of Pannonia, Veszprém, Hungary. She obtained her Ph.D. (conscious knowledge management in knowledge economy) in Economics and Management in 2008. Nóra has been teaching a variety of management master courses including Strategic Human Resource Management, Globalization and Organizational Culture, and Competence Management.

Edit Komlósi is a lecturer at the Department of Management, University of Pannonia, Veszprém, Hungary, and a finishing Ph.D. candidate at the Business School, University of Derby, UK. Her thesis concerns are emotional intelligence of practicing managers and their relation to individual performance within organisational culture. Edit has been involved in a variety of undergraduate, master and MBA courses such as Business Communication, International Business Communication and Comprehensive Business Studies.

Cintia Szenteleki is studying Management and Leadership at the Department of Management, University of Pannonia, Veszprém, Hungary, where she carries out researches in the field of emotional intelligence and work-life balance in János Harsányi Student Hostel Specialized in Economics. Her areas of interests are service management, project management, and competence management.

Erika Viktória Tóth is an MSc student at the Department of Management, University of Pannonia, Veszprém, Hungary. She is currently studying Management and Leadership. She is a member of János Harsányi Student Hostel Specialized in Economics. She participates in various competitions and conferences. Her field of research is knowledge management, knowledge sharing and emotional intelligence. Her area of interests includes project management, logistics, product and service management, and marketing management.

\author{
Exploring \\ Emotional \\ Intelligence \\ Trait Enablers \\ for Knowledge \\ Sharing: \\ An Empirical \\ Study
}

